\title{
Synthesis of Novel $\sigma-\pi$ Conjugated Polymers by Alternating Boration Copolymerization between 1,2-Diethynyl-1,1,2,2-tetramethyldisilane and Aromatic Diynes
}

\author{
Noriyoshi MATSUMI and Yoshiki CHUJO ${ }^{\dagger}$ \\ Department of Polymer Chemistry, Graduate School of Engineering, Kyoto \\ University, Yoshida, Sakyo-ku, Kyoto 606-8501, Japan
}

(Received February 3, 2000; Accepted December 2, 2000)

\begin{abstract}
Novel $\sigma-\pi$ conjugated polymers were prepared by alternating boration copolymerization between 1,2diethynyl-1,1,2,2-tetramethyldisilane and aromatic diynes using diphenylbromoborane. The gel permeation chromatographic analysis (GPC) showed that the number average molecular weights $\left(M_{\mathrm{n}}\right)$ of the obtained polymers were several thousands. For example, $M_{\mathrm{n}}$ of the polymer produced from 2,7-diethynylfluorene was 5700 (yield $30 \%$ ). The polymers were soluble in common organic solvents such as THF, chloroform and dichloromethane. The polymer having the fluorene unit was moderately fluorescent. The structures of the polymers were supported by ${ }^{1} \mathrm{H}$ NMR, ${ }^{11} \mathrm{~B} N M R,{ }^{29} \mathrm{Si} N M R$, and IR spectra.
\end{abstract}

KEY WORDS Conjugated Polymer / Inorganic Polymer / Boration Polymerization / Organoboron Polymer / Organosilicon Polymer /

The preparation of the organosilicon polymers having silylene units and $\pi$-conjugated units in the alternating arrangement has been a very interesting subject due to the $\sigma-\pi$ conjugative interaction ${ }^{1}$ along the polymer chains. Since these materials are potentially important as semiconducting or conducting materials, ${ }^{2}$ precursors for silicon carbide ceramics and light emitting materials, ${ }^{3}$ their preparative methods have also been widely developed. For example, a Wurtz type polymerization of bis(chloromethylphenylsilyl)benzene ${ }^{4}$ quenching of the aromatic bifunctional Grignard reagents (or organolithium reagents) with dichlorodisilane ${ }^{5}$ or a ring-opening polymerization of 1,1,2,2-tetramethyl-3,4-benzo-1,2disilacyclobutene with a Lewis acid, ${ }^{6}$ each affords the corresponding poly(disilanylene-arylene)s respectively. On the other hand, we have previously explored various methodologies for the preparation of organoboron mainchain polymers by means of boration polymerization. ${ }^{7}$ During the course of the work, some polymers having relatively high stability toward air-oxidation and mois-

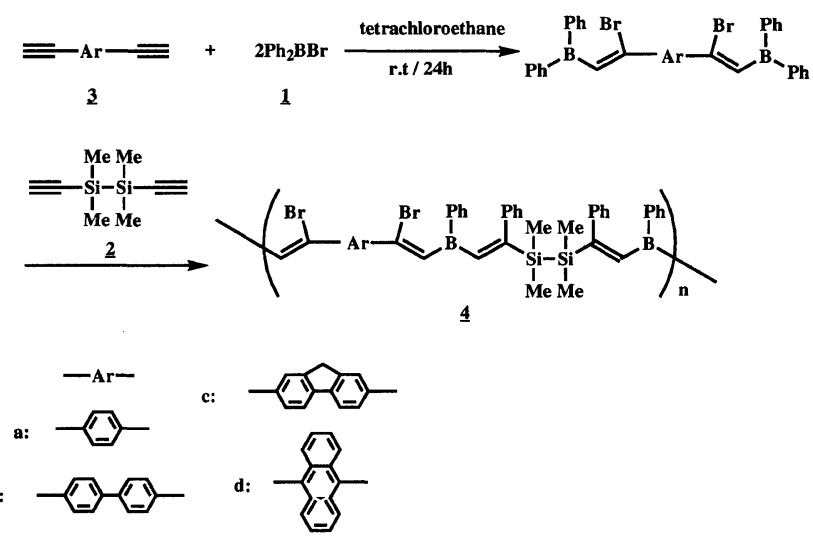

Scheme 1.

${ }^{\dagger}$ To whom correspondence should be addressed. ture were prepared and they are interesting as a new class of boron containing materials. ${ }^{8}$ Very recently, it was found that the UV-vis spectra of organoboron polymers produced from aromatic diynes have the absorption maxima in the visible region, due to the extension of $\pi$-conjugation length via vacant $\mathrm{p}$-orbital of boron atom. ${ }^{9}$ Furthermore, taking advantage of different reactivity between haloboration and phenylboration, an alternating boration polymerization method was explored. ${ }^{10}$ In this paper, an alternating boration polymerization between 1,2-diethynyl-1,1,2,2-tetramethyldisilane (2) and aromatic diynes (3) was undertaken to give the novel boron-containing $\sigma-\pi$ conjugated polymers (Scheme 1).

\section{RESULTS AND DISCUSSION}

An alternating boration polymerization between 1,2diethynyl-1,1,2,2-tetramethyldisilane (2) and 2,7diethynylfluorene (3c) was first examined as follows. To a tetrachloroethane solution of $\mathbf{3 c}, 2$ molar equiv of diphenylbromoborane (1) were added under nitrogen atmosphere at room temperature and the reaction mixture was stirred for $24 \mathrm{~h}$ (1st step; selective haloboration). From the ${ }^{1} \mathrm{H}$ NMR measurement, disappearance of the acetylene proton ( $3.13 \mathrm{ppm}$ ) was observed. In the 2nd step, 1 molar equiv of $\mathbf{2}$ was added and the mixture was reacted at higher temperature $\left(60-130^{\circ} \mathrm{C}\right)$ for $1-2 \mathrm{~h}$ (phenylboration polymerization). After reprecipitation into $n$-hexane, the polymer (4c) was obtained as a brown powder. The polymer was soluble in common organic solvents such as THF, chloroform and dichloromethane. The gel permeation chromatographic analysis (THF, PSt standards) showed that the number average molecular weights of the polymers were several thousands. The results of the polymerization under various reaction conditions of the 2nd step are summarized in Table I. From these results, the best condition was optimized to be at $80^{\circ} \mathrm{C}$ for $2 \mathrm{~h}$ (Run 3 ). Under the severe reaction conditions (Runs 5 and 6), relatively high molecular weights 
Table I. Alternating haloboration-phenylboration copolymerization between 2,7-diethynylfluorene (3c) and 1,2-diethynyl-1,1,2,2-tetramethyldisilane (2) using diphenylbromoborane (1) under various reaction conditions ${ }^{\mathrm{a}}$

\begin{tabular}{|c|c|c|c|c|c|c|c|c|}
\hline Run & Temp $/{ }^{\circ} \mathrm{C}$ & Time/h & Conc. $/ \mathrm{M}^{\mathrm{b}}$ & $\begin{array}{c}\text { Ratio/mol } \\
(\mathbf{1} / \mathbf{3 c} / \mathbf{2})\end{array}$ & $M_{\mathrm{n}}^{\mathrm{c}}$ & $M_{\mathrm{w}}^{\mathrm{c}}$ & $M_{\mathrm{w}} / M_{\mathrm{n}}^{\mathrm{c}}$ & Yield $/ \%^{\mathrm{d}}$ \\
\hline 1 & 60 & 2 & 2.0 & $2.00 / 0.974 / 0.907$ & 3500 & 9700 & 2.8 & 35 \\
\hline 2 & 80 & 1 & 2.0 & $2.00 / 0.962 / 0.924$ & 2000 & 5300 & 2.6 & 47 \\
\hline 3 & 80 & 2 & 2.0 & $2.00 / 0.934 / 0.893$ & 5700 & 19500 & 3.4 & 30 \\
\hline 4 & 80 & 2 & 0.5 & $2.00 / 0.960 / 0.884$ & 3900 & 13700 & 3.5 & 18 \\
\hline 5 & 115 & 2 & 2.0 & $2.00 / 0.928 / 0.928$ & 7700 & 38700 & 5.1 & 24 \\
\hline 6 & 130 & 2 & 2.0 & $2.00 / 0.975 / 0.937$ & 4900 & 27600 & 5.6 & 32 \\
\hline
\end{tabular}

${ }^{a}$ All reactions were carried out under nitrogen using tetrachloroethane as a solvent. ${ }^{\mathrm{b}}$ Concentration of $1 .{ }^{\mathrm{c}} \mathrm{GPC}(\mathrm{THF})$ polystyrene standards. ${ }^{\mathrm{d}}$ Isolated yields after reprecipitation into $n$-hexane.

were attained, however, the produced polymers had fairly crosslinked structure due to further phenylboration of $\mathrm{B}-\mathrm{Ph}$ in the side-chain.

The structures of the polymers were supported by ${ }^{1} \mathrm{H}$, ${ }^{11} \mathrm{~B},{ }^{29} \mathrm{Si} \mathrm{NMR}$, and IR spectra. For example, in the ${ }^{1} \mathrm{H}$ NMR spectrum of 4c (Figure 1a), methyl groups on the silylene moiety appeared at $0.23 \mathrm{ppm}$ and the methylene protons and other aromatic protons (including vinyl group) were observed at $3.85 \mathrm{ppm}$ and $7.45 \mathrm{ppm}$ respectively. The ${ }^{11} \mathrm{~B}$ NMR spectrum of $4 \mathbf{c}$ (Figure $1 \mathrm{~b}$ ) had mainly only one peak (30.3 ppm) attributable to dialkenylborane. In the ${ }^{29} \mathrm{Si} \mathrm{NMR}$ spectrum (Figure 1c), simple one peak due to the disilanylene unit was observed at $-27.8 \mathrm{ppm}$. This indicates that the disilanylene structure was not affected by the polymerization condition.

The results of the polymerization using various aromatic diynes are listed in Table II. As diyne monomers, 1,4-diethynylbenzene(3a) and 1,6-diethynylbiphenyl(3b) also gave the corresponding soluble polymers. However, the reaction using 1,9-diethynylanthracene (3d) was unsuccessful due to poor solubility of 3d.

The optical properties of the polymers obtained were investigated by the measurements of UV-vis spectra (in $\mathrm{CHCl}_{3}$, at room temperature) and the fluorescence emission spectra (in $\mathrm{CHCl}_{3}$ at room temperature; excitation wavelength at $300 \mathrm{~nm}$ ). The both spectra of $4 \mathbf{c}$ are represented in Figure 2. In the UV-vis spectrum (a), two absorption maxima were observed at 284 and $315 \mathrm{~nm}$, the latter might be due to $\sigma$ - $\pi$ interaction via boron atom. ${ }^{12}$ In the fluorescence emission spectrum (b), blue light emission (419 and $449 \mathrm{~nm}$ ) was observed in a moderate intensity. However, in the case of the polymer $4 \mathrm{a}$ and $4 \mathrm{~b}$, just a weak emission was observed. This implies that $\sigma$ $\pi$ interaction via boron atom is not so effective.

The air stability of 4c was investigated by an airbubbling experiment. Air was bubbled into a THF solution of $4 \mathbf{c}$ and the change of the molecular weight was monitored by the GPC measurement. After the air bubbling for $48 \mathrm{~h}$, no obvious decrease in molecular weight was observed. This indicates the relatively high stability of the organoboron unit. However, in the IR spectrum of 4c after the air-bubbling, a strong $\mathrm{Si}-\mathrm{O}-\mathrm{Si}$ stretching was observed at $1030-1070 \mathrm{~cm}^{-1} .12$

In conclusion, a novel methodology for the preparation of $\sigma-\pi$ conjugated polymers was explored by alternating boration copolymerization between 1,2-diethynyl1,1,2,2-tetramethyldisilane (2) and aromatic diynes (3). The polymers obtained (4) were soluble in common organic solvents such as THF, chloroform and dichloromethane. However, $\sigma-\pi$ interaction via boron atom

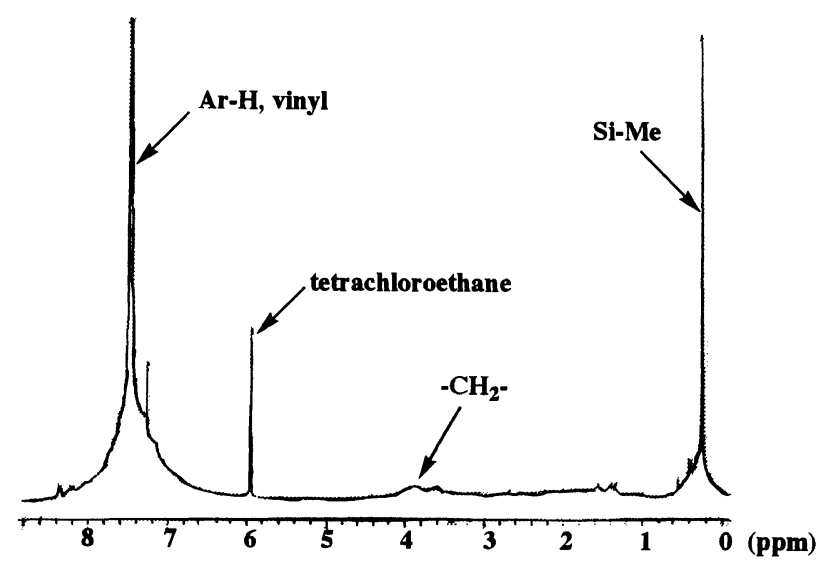

(a)

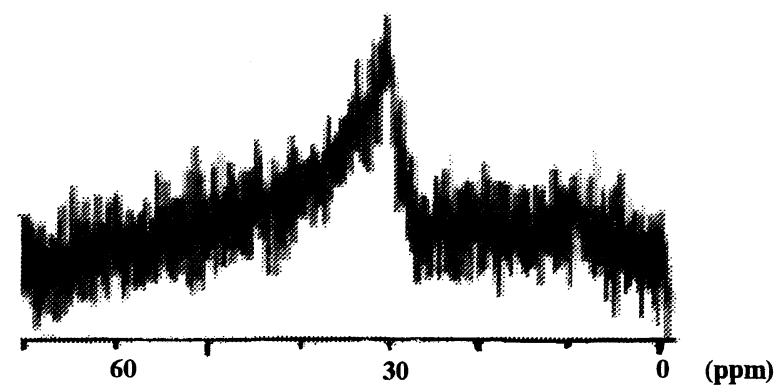

(b)

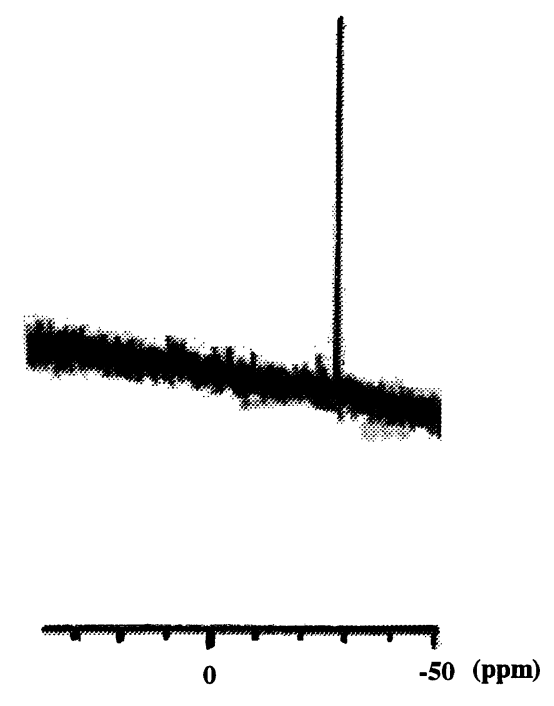

(c)

Figure 1. ${ }^{1} \mathrm{H}(\mathrm{a}),{ }^{11} \mathrm{~B}(\mathrm{~b})$, and ${ }^{29} \mathrm{Si} \mathrm{NMR}(\mathrm{c})$ spectra of $4 \mathbf{c}$. 
Table II. Alternating haloboration-phenylboration copolymerization

between 1,2-diethynyl-1,1,2,2-tetramethyldisilane (2) and various diynes $(3)^{a}$

\begin{tabular}{|c|c|c|c|c|c|c|c|}
\hline Diynes & & $1 / 3 / 2$ & Conc. $/ \mathrm{M}^{\mathrm{b}}$ & $M_{\mathrm{n}}^{\mathrm{c}}$ & $M_{\mathrm{w}}^{\mathrm{c}}$ & $M_{\mathrm{w}} / M_{\mathrm{n}}^{\mathrm{c}}$ & Yield $/ \%^{\mathrm{d}}$ \\
\hline & $(\mathbf{3 a})$ & $2.00 / 0.972 / 0.890$ & 2.0 & 8400 & 34000 & 4.1 & 50 \\
\hline & $(\mathbf{3 b})$ & $2.00 / 0.976 / 0.953$ & 1.0 & 2500 & 4500 & 1.8 & 56 \\
\hline & $(\mathbf{3 c})$ & $2.00 / 0.934 / 0.893$ & 2.0 & 5700 & 19500 & 3.4 & 30 \\
\hline & $(\mathbf{3 d})$ & $2.00 / 0.931 / 0.888$ & 0.7 & \multicolumn{4}{|c|}{ No Polymerization } \\
\hline
\end{tabular}

${ }^{\mathrm{a}}$ Reactions were carried out in tetrachloroethane at $80^{\circ} \mathrm{C}$ for $2 \mathrm{~h} .{ }^{\mathrm{b}}$ Concentration of $1 .{ }^{\mathrm{c}}$ GPC (THF) polystyrene standards. ${ }^{\mathrm{d}}$ Isolated yields after reprecipitation into $n$-hexane.

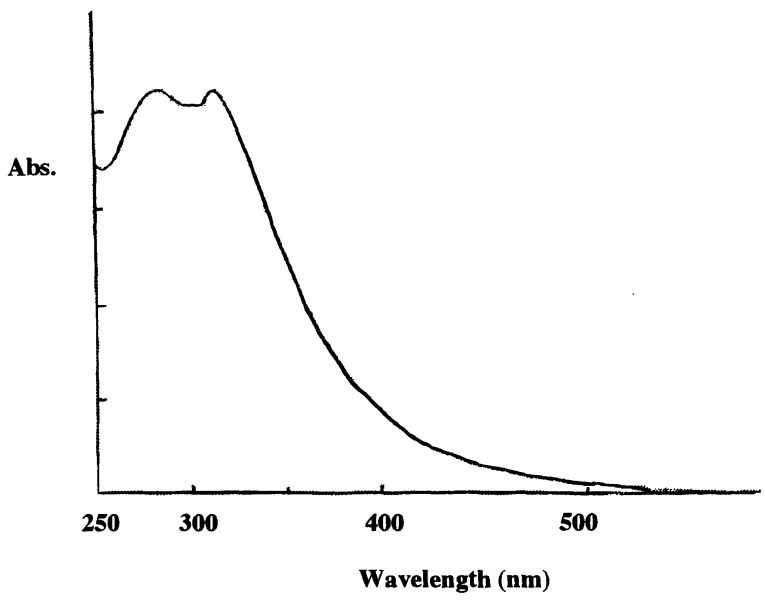

(a)

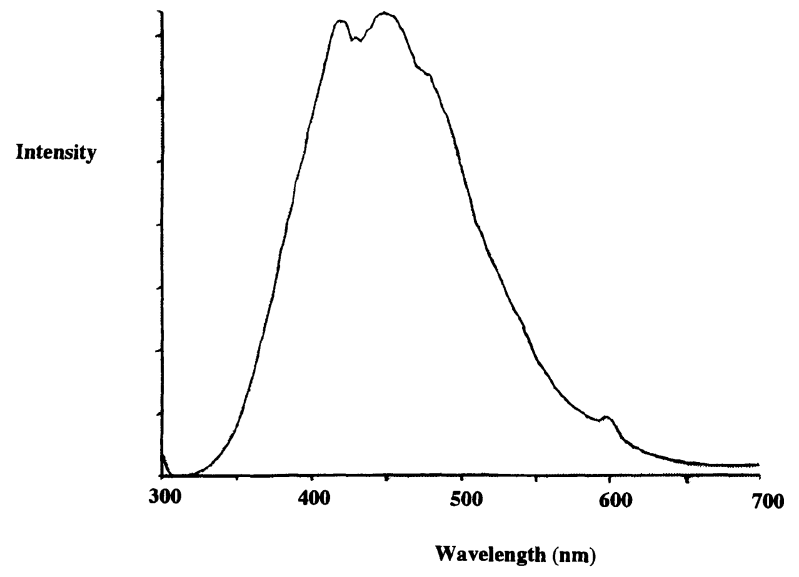

(b)

Figure 2. UV-vis absorption (in $\mathrm{CHCl}_{3}$, at room temperature); (a) and PL emission (in $\mathrm{CHCl}_{3}$, at room temperature; excitated at $300 \mathrm{~nm}$ ); (b) spectra of $4 \mathrm{c}$.

was not so effective except in $\mathbf{4 c}$, because of the presence of less planar trialkenylborane unit formed by further phenylboration reaction.

\section{EXPERIMENTAL}

\section{Materials and Instruments}

Tetrachloroethane was dried over calcium chloride and distilled before use. Diphenylbromoborane $(\mathbf{1}),{ }^{13}$ aromatic diynes $(3)^{14}$ and 1,1,2,2-tetramethyl-1,2,diethynyldisilane $(2)^{15}$ were prepared according to the reported procedures. ${ }^{1} \mathrm{H},{ }^{11} \mathrm{~B}$, and ${ }^{29} \mathrm{Si}$ NMR spectra were recorded in $\mathrm{CDCl}_{3}$ on a JEOL EX-270 instrument. Gel permeation chromatographic analysis was carried out on a TOSOH G3000HXI by using THF as an eluent after calibration with polystyrene standards. IR spectra were obtained on a Perkin-Elmer 1600 spectrometer. UV-vis spectra were recorded on a JASCO V-530 spectrophotometer. Fluorescence emission spectra were recorded on a Perkin-Elmer LS 50 B luminescence spectrometer.

\section{Alternating Boration Copolymerization between $\mathbf{2}$ and $\mathbf{3}$}

Typically, the polymerization between 2 and 3c was carried out as follows. To a tetrachloroethane solution of $3 \mathrm{c}$ (103.2 mg, $0.482 \mathrm{mmol}), 2$ molar equiv of $1(252.7 \mathrm{mg}$, $1.032 \mathrm{mmol}$ ) were added under nitrogen atmosphere at room temperature and the reaction mixture was stirred for $24 \mathrm{~h}$ (1st step; selective haloboration). From the ${ }^{1} \mathrm{H}$ NMR measurement, disappearance of the acetylene proton $(3.13 \mathrm{ppm})$ was observed. In the 2 nd step, 1 molar equiv of 2 ( $76.7 \mathrm{mg}, 0.461 \mathrm{mmol}$ ) was added and the mixture was reacted at higher temperature $\left(80^{\circ} \mathrm{C}\right)$ for $2 \mathrm{~h}$ (phenylboration polymerization). After reprecipitation into $n$-hexane, the polymer (4c) was obtained as a brown powder $(120.5 \mathrm{mg}, 30 \%)$. ${ }^{1} \mathrm{H}$ NMR $(\delta, \mathrm{ppm}) 0.23\left(\mathrm{Si}^{-} \mathrm{CH}_{3}\right.$, $12 \mathrm{H}), 3.85\left(\mathrm{CH}_{2}, 2 \mathrm{H}\right), 7.45(\mathrm{Ar}-\mathrm{H}$, vinyl, $30 \mathrm{H}) .{ }^{11} \mathrm{~B}$ NMR $(\delta, \mathrm{ppm}) 30.3 .{ }^{29} \mathrm{Si} \mathrm{NMR}(\delta, \mathrm{ppm})-27.8 . \mathrm{IR}\left(\mathrm{cm}^{-1}\right) 1600$ $\left(v_{\mathrm{C}=\mathrm{C}}\right)$.

4a and $\mathbf{4 b}$ were similarly prepared as discribed for $\mathbf{4 c}$. 4a; $251.6 \mathrm{mg}$ (1.027 $\mathrm{mmol})$ of $1,76.1 \mathrm{mg}(0.457 \mathrm{mmol})$ of 2 and $63.0 \mathrm{mg}(0.499 \mathrm{mmol})$ of $3 \mathbf{a} ; 178.0 \mathrm{mg}$ of $\mathbf{4 a}(50 \%)$ ${ }^{1} \mathrm{H}$ NMR $(\delta, \mathrm{ppm}) 0.19\left(\mathrm{Si}-\mathrm{CH}_{3}, 12 \mathrm{H}\right), 7.24(\mathrm{Ar}-\mathrm{H}$, vinyl, $28 \mathrm{H})$. IR $\left(\mathrm{cm}^{-1}\right) 1600\left(v_{\mathrm{C}=\mathrm{C}}\right) .4 \mathbf{b} ; 253.2 \mathrm{mg}(1.033 \mathrm{mmol})$ of $1,81.8 \mathrm{mg}(0.492 \mathrm{mmol})$ of 2 and $102.0 \mathrm{mg}(0.504$ $\mathrm{mmol})$ of $3 \mathbf{b} ; 235.2 \mathrm{mg}$ of $4 \mathbf{b}(56 \%){ }^{1} \mathrm{H} \mathrm{NMR}(\delta, \mathrm{ppm})$ $0.25\left(\mathrm{Si}-\mathrm{CH}_{3}, 12 \mathrm{H}\right), 7.39\left(\mathrm{Ar}-\mathrm{H}\right.$, vinyl, 32H). IR $\left(\mathrm{cm}^{-1}\right)$ $1601\left(v_{\mathrm{C}=\mathrm{C}}\right)$.

\section{REFERENCES}

1. a) M. Ishikawa and M. Kumada, Adv. Organomet. Chem., 19 , 51 (1981). b) H. Sakurai, S. Tasaka, and M. Kira, J. Am. Chem. Soc., 94, 9285 (1972). c) H. Sakurai, J. Organomet. Chem., 200, 261 (1980). d) H. Shizuka, Y. Sato, Y. Ueki, M. 
Ishikawa, and M. Kumada, J. Chem. Soc., Faraday Trans. 1, 80, 341 (1984).

2. a) J. Ohshita, D. Kanaya, M. Ishikawa, and T. Yamanaka, Chem. Express., 5, 489 (1990). b) J. Ohshita, D. Kanaya, M. Ishikawa, T. Koike, and T. Yamanaka, Macromolecules, 24, 2106 (1991).

3. a) P. F. van Hutten, R. E. Gill, J. K. Herrema, and G. Hadziioannou, J. Phys. Chem., 99, 3218 (1995). b) J. K. Herrema, P. F. van Hutten, R. E. Gill, J. Wildeman, R. H. Wieringa, and G. Hadziioannou, Macromolecules, 28, 8102 (1995). c) M. Fang, A. Watanabe, and M. Matsuda, Macromolecules, 29, 6807 (1996).

4. M. Ishikawa, H. Z. Ni, and K. Matsusaki, J. Polym. Sci., Polym. Lett. Ed., 22, 669 (1984).

5. M. Fang, A. Watanabe, and M. Matsuda, J. Organomet. Chem., 489, 15 (1995).

6. K. Shiina, J. Organomet. Chem., 310, C57 (1986).

7. a) Y. Chujo, I. Tomita, Y. Hashiguchi, H. Tanigawa, E. Ihara, and T. Saegusa, Macromolecules, 24, 345 (1991). b) Y. Chujo, I. Tomita, Y. Hashiguchi, and T. Saegusa, Macromolecules, 25, 33 (1992). c) Y. Chujo, I. Tomita, and T. Saegusa, Macromolecules, 23, 687 (1990). (d) N. Matsumi and Y. Chujo, Polym. Bull., 38, 531 (1997).
8. a) Y. Chujo, I. Tomita, N. Murata, H. Mauermann, and T. Saegusa, Macromolecules, 25, 27 (1992). b) Y. Chujo, ACS. Symp. Ser., 572, 398 (1994).

9. N. Matsumi, K. Naka, and Y. Chujo, J. Am. Chem. Soc., 120, 5112 (1998)

10. N. Matsumi, K. Kotera, K. Naka, and Y. Chujo, Macromolecules, 31, 3155 (1998). As reported in ref 11, haloboration toward aromatic acetylene takes place under mild conditions, while the phenylboration requires severe reaction conditions. The high degree of the unit alternation was confirmed by ${ }^{11} \mathrm{~B}$ NMR measurements.

11. M. F. Lappert and B. Prokai, J. Organomet. Chem., 1, 384 (1964).

12. The peak at $315 \mathrm{~nm}$ disappeared after air-oxidation of the disilanylene unit. After the air-oxidation, PL intensity was fairly decreased.

13. W. Haubold, J. Herdlte, W. Gollinger, and W. Einholz, J. Organomet. Chem., 315, 1 (1986).

14. S. Takahashi, Y. Kuroyama, K. Sonogashira, and N. Hagihara, Synthesis, 627 (1980).

15. T. Iwahara, S. Hayase, and R. West, Macromolecules, 23 $1298(1990)$ 